\title{
Taurine and Neonatal Nutrition
}

\author{
Deepak Chawla ${ }^{1}$ (D)
}

Received: 16 August 2018 / Accepted: 21 August 2018 / Published online: 6 September 2018

(C) Dr. K C Chaudhuri Foundation 2018

Taurine is one of the sulfur-containing amino-acids. Although, not a part of any protein, it is widely distributed in body and is the most abundant free amino acid in human breast milk. High concentration of taurine is found in brain, mature retina and inner ear [1]. In neural tissues, taurine functions as an intracellular organic osmolyte, thus regulating the neural cell volume. By modulating the intracellular calcium homeostasis, it has membrane stabilizing effect. Taurine also has cytoprotective effect against oxidative damage and glutamate-induced excitotoxicity [2]. Preterm neonates are more vulnerable to taurine deficiency due to low capacity for endogenous synthesis and higher renal loss. Human milk contains adequate amount of taurine and neonates fed with human milk may grow slower than neonates fed with formula milk but have better neurodevelopmental outcome [3]. Higher taurine content of human milk has been assigned as one of the reasons of beneficial effects of human milk feeding on neurodevelopmental outcome [4]. Prolonged feeding with taurinedeficient formula milk or parenteral nutrition has been associated with retinal degeneration, delayed auditory maturation, decreased bile acid secretion, lower fat absorption and hepatic cholestasis [1]. Recognition of potential harmful effects of taurine deficiency in the last decade of the twentieth century, led to recommendations about minimal taurine content in formula milk. Now, all formula milk preparations are supplemented with taurine to match the intake during human milk feeding (4.5-9 $\mathrm{mg} / \mathrm{kg} / \mathrm{d})$ [5].

A few randomized controlled trials were conducted before taurine supplementation of formula milk became a routine practice. All these trials, totaling 9 in number are small underpowered studies with cumulative enrolment of 216 low birth weight neonates [2]. Not all the clinically important outcomes have been reported in these trials. Therefore, reaching a meaningful conclusion about beneficial or harmful effects of taurine

Deepak Chawla

drdeepakchawla@gmail.com

1 Department of Neonatology, Government Medical College Hospital, Chandigarh 160 030, India supplementation is not easy. Cao et al. present the findings of their systematic review on taurine supplementation in this issue of the journal [6]. Like results of a Cochrane review on this topic, no clinically beneficial effect of taurine supplementation was observed on short-term physical growth of neonates [2]. None of the studies have reported long-term effects on the neurodevelopment. On the contrary, studies in term infants and in animal models suggest delayed auditory maturation with taurine supplementation [7]. No fresh studies have been conducted after 1993. Due to lack of evidence supporting or against it, routine taurine supplementation of preterm formula preparations to mimic the intake of breastfed infants will continue. However, is there a role of higher intake of taurine during any development stage? Careful studies are warranted to study the effect of taurine in selective subgroups like neonates born at extremely prematurity or with birth asphyxia.

\section{Compliance with Ethical Standards}

Conflict of Interest None.

\section{References}

1. Ripps H, Shen W. Review: taurine: a "very essential" amino acid. Mol Vis. 2012;18:2673-86.

2. Verner A, Craig S, McGuire W. Effect of taurine supplementation on growth and development in preterm or low birth weight infants. Cochrane Database Syst Rev. 2007:CD006072.

3. Wharton BA, Morley R, Isaacs EB, Cole TJ, Lucas A. Low plasma taurine and later neurodevelopment. Arch Dis Child Fetal Neonatal Ed. 2004;89:F497-8.

4. Heird WC. Taurine in neonatal nutrition-revisited. Arch Dis Child Fetal Neonatal Ed. 2004;89:F473-4.

5. Klein CJ. Nutrient requirements for preterm infant formulas. J Nutr. 2002;132:1395S-577S.

6. Cao SL, Jiang H, Niu SP, Wang XH, Du S. Effects of taurine supplementation on growth in low birth weight infants: a systematic review and meta-analysis. Indian J Pediatr. 2018. https://doi.org/10. 1007/s12098-018-2609-0.

7. Dhillon SK, Davies WE, Hopkins PC, Rose SJ. Effects of dietary taurine on auditory function in full-term infants. Adv Exp Med Biol. 1998;442:507-14. 